\title{
Ralf Forsbach
}

Die Medizinische Fakultät der Universität Bonn im „Dritten Reich“ 



\title{
Die
}

Medizinische Fakultät der Universität Bonn im „Dritten Reich“

\author{
Von \\ Ralf Forsbach
}

R. Oldenbourg Verlag München 2006 


\section{Diese Publikation wurde gefördert mit Mitteln der}

Alfried Krupp von Bohlen

und Halbach-Stiftung

und von

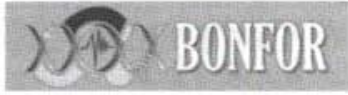

Bibliografische Information Der Deutschen Bibliothek

Die Deutsche Bibliothek verzeichnet diese Publikation in der Deutschen Nationalbibliografie; detaillierte bibliografische Daten sind im Internet über $<$ http://dnb.ddb.de $>$ abrufbar.

C 2006 R. Oldenbourg Wissenschaftsverlag GmbH, München

Rosenheimer Straße 145, D-81671 München

Internet: http://www.oldenbourg.de

Das Werk einschließlich aller Abbildungen ist urheberrechtlich geschützt. Jede Verwertung außerhalb der Grenzen des Urheberrechtsgesetzes ist ohne Zustimmung des Verlages unzulässig und strafbar. Dies gilt insbesondere für Vervielfältigungen, Übersetzungen, Mikroverfilmungen und die Einspeicherung und Bearbeitung in elektronischen Systemen.

Umschlaggestaltung: Dieter Vollendorf

Umschlagbild: Ruinen der Kliniken an der Theaterstraße, 1946. Stadtarchiv

Bonn. Foto: Robert Frei

Gedruckt auf säurefreiem, alterungsbeständigem Papier (chlorfrei gebleicht). Gesamtherstellung: Oldenbourg Druckerei Vertriebs GmbH \& Co. KG, München

ISBN-13: 978-3-486-57989-5

ISBN-10: 3-486-57989-4 